\title{
Account-to-Account Electronic Money Transfers: Recent Developments in the United States
}

\author{
Oz Shy
}

\begin{abstract}
:
This paper reviews recent developments in online and mobile banking in the United States that provide bank account holders with low-cost interfaces to manage account-to-account electronic money transfers. The paper analyzes the emerging decentralized market in which A2A money transfers are becoming available in the United States and compares it with the A2A market in other countries. The paper constructs analytical examples to explain and evaluate the structure of the emerging U.S. market and discusses possible policy actions that may enhance the use of A2A money transfers in the United States.
\end{abstract}

Keywords: account-to-account money transfers, person-to-person money transfers, online banking, mobile banking, payment networks

\section{JEL Classifications: E42, G29, D14}

Oz Shy is a senior economist at the Federal Reserve Bank of Boston and a member of the Consumer Payments Research Center in the research department.

I thank two anonymous referees, Kevin Foster, Vikram Jambulapati, Suzanne Lorant, Scott Schuh, Bob Triest, and Hanbing Zhang for all their help and guidance.

This paper presents preliminary analysis and results intended to stimulate discussion and critical comment. The views expressed herein are those of the author and do not indicate concurrence by other members of the research staff or principals of the Federal Reserve Bank of Boston, the Board of Governors, or the Federal Reserve System.

This paper, which may be revised, is available on the web site of the Federal Reserve Bank of Boston at http://www.bostonfed.org/economic/ppdp/index.htm.

version of: October 12, 2011 


\section{Introduction}

\subsection{Motivation and goals}

Account-to-account (A2A) electronic money transfer is a low-cost platform that does not require any face-to-face interaction to transfer money between accounts held by different holders. In general, electronic transfers involve commercial transactions (paying bills to small businesses outside the point of sale) and noncommercial transactions, such as money transfers within a circle of family and friends.

For reasons analyzed in this paper, account holders in the United States are being introduced to A2A electronic funds transfers at a very late stage in the development of this technology compared with other developed and developing countries. This paper aims to achieve the following goals:

(a) To explain the emerging decentralized pattern of providers by which A2A money transfers are slowly becoming available in the United States, led by money transmitters, such as PayPal and Amazon Payments;

(b) To construct an analytical framework for evaluating this emerging market structure;

(c) To identify why electronic funds transfers among households and small businesses are still relatively rare in the United States compared with practices in other countries.

\subsection{Some terminology}

This paper studies money transfers between bank accounts owned mainly by individuals. The term A2A refers to electronic transfers between individuals, with small businesses classified as individuals in this context. Money transfers are generally classified by the type of entities involved and the direction of transfer. The most common types of electronic money transfers classified by the entities involved are: (i) person-to-person (P2P), (ii) person-to-business (P2B), (iii) business-toperson (B2P), and (iv) business-to-business (B2B). Adding local and federal governments, transfers are also made from (v) person-to-governments (P2G), (vi) governments-to-person (G2P), (vii) business-to-governments (B2G), and (viii) governments-to-business (G2B). Leaving governments aside, electronic P2P transfers hardly exist in the United States. B2P transfers are also rare except for employment-related direct deposits. P2P transfers are either cash based or accomplished by 
writing personal paper checks. In 2009, P2P payments constituted 5 percent of total payments (Foster et al. 2011, Tables 21 and 25), with 3.6 percent of the transfers using cash, while the rest used checks, money orders, debit and credit cards, and electronic payments. ${ }^{1}$

A2A money transfer differs from online bill payment (OLBP). In an A2A transfer, the payee provides the payer with the payee's bank account information. This paper defines an A2A money transfer as any transfer performed via online or mobile banking in which the sender logs into his bank account and keys in the transfer recipient's routing and account number. ${ }^{2}$ In OLBP, payments, such as those made monthly to pay bills from telecommunications, gas, electric, and insurance companies, the payer does not know the payee's account information; instead, payment is made using the Internet via the website of a bank, company, or other institution that issued the bill. In addition to applying to P2P transfers, A2A applies more to payments made by households to small businesses than to large companies; an example of such a P2B would be a household paying a small business (dentist).

Some interfaces bypass the need for the sender to key in the recipient's bank account information, by sending email to the recipient asking the recipient to key in this information. All that the recipient has to do is to give the sender her account details and/or her email address. Small businesses can print this information on the invoices they send to customers.

For the purpose of this paper, direct transfers are defined as money transfers between two bank accounts with no need to prefund the sending account with funds from another bank's account or to redeposit the transferred funds from the receiving account into another bank's account. For the past few years many commercial banks did provide one form of direct A2A transfers via FedWire. The problem was (and still is) that from households' perspective, commercial banks set prohibitively costly fees: for example, the fee to send and, separately, the fee to receive a transfer has ranged from $\$ 10$ to $\$ 30$ per transfer.

Indirect transfers are defined here as transfers made by prefunding an account held at a nonbank

\footnotetext{
${ }^{1}$ These numbers are for P2P transfers only (small businesses are excluded). Also, note that most debit and credit cards do not provide direct P2P transfer services. Hence, most likely, respondents used a third party, such as PayPal, for P2P transfers that are funded by debit and credit cards. Section 2.2 elaborates on this issue.

${ }^{2}$ A routing transit number (RTN), also known as the American Bankers Association (ABA) number, is a nine-digit bank code that appears on the bottom of checks to identify a financial institution in the United States. This code is also used by Federal Reserve Banks and the automated clearing house to process electronic funds transfers.
} 
third party, or transfers that involve having to redeposit money received into a bank account. Transfers via nonbank money transmitters (such as PayPal and Amazon Payments) require the sender to prefund a nonbank account either via a bank account (with the use of an automated clearing house $(\mathrm{ACH}))$, or with a debit or credit card. Finally, the terms "platform" and "network," are used interchangeably in this paper.

\subsection{Major findings and organization}

The market structure of A2A money transfers in the United States has emerged differently from the experience in Europe and has resulted in a different market structure.In the United States, the market structure is decentralized, consisting of various groups of banks and isolated money transmitters that operate on different networks.

Europe's lead in adopting electronic A2A funds transfers much earlier than the United States cannot be explained by earlier adoption of online banking or online bill payment in Europe. In fact, Shy (2010) has shown that adoption patterns were very similar on the two continents. Instead, the European lead in electronic P2P was a natural extension of the "old" Giro payment networks, which were accessible to all consumers via many European post offices and financial institutions. In addition, more recent heavy involvement by the European Central Bank and national central banks have also played a major role in transforming national electronic payment networks into trans-European networks.

The United States has followed a different path. Unlike consumers in other countries, most consumers in the United States first gained access to low-cost A2A money transfers outside the banking industry. In addition, perhaps because of the heavy use of paper checks, the United States Postal Service has not been involved in providing payment services as was the case in some European countries where post offices ran the Postal Giro networks that were connected to commercial banks. In the United States, nonbank money transmitters, such as PayPal and Amazon Payments, provide registered users with an online interface to transfer money among registered users. Senders can fund their transfer from their external bank accounts without any fee, or by a credit or debit card (for a fee). Receivers can then transfer their balance to their bank account or spend it using a debit card. Only in the past two years have several commercial banks begun to 
integrate A2A money transfer services with online banking.

During the past 90 years, the Fed was (and still is) involved in check clearing while the federal government has continued its involvement via the Check 21 Act of 2003. These efforts may have contributed to the slow adoption of electronic A2A transfers. The recent introduction of new A2A technologies reveals that the United States is heading for multiple A2A transfer networks formed by groups of commercial banks and isolated money transmitters. It is hard to tell whether these "silos" are the result of the large number of banks in the United States, lack of coordination, or both. Regardless, most account holders in the country still lack low-cost access to online transfer services whereby they can transfer money to any other account within the nation.

The remainder of the paper is organized as follows. Section 2 analyzes the fundamental question of whether the slow introduction (to some degree a missing market) in the United States reflects a market failure. Section 3 provides data and international comparisons of the use of electronic funds transfers. Section 4 reports and analyzes recent developments in A2A money transfers in the United States. Section 5 constructs analytical frameworks to explain the coexistence of multiple payment networks and to evaluate the possibility of adoption failures. Section 6 briefly discusses policy options. Section 7 concludes.

\section{Is There a Market Failure?}

The possible market failure discussed in this section refers to a missing market. Market failure occurs if the sum of consumer benefits and bank profit (social welfare) exceeds the cost of bringing a standardized service to a market, but, in reality, there are insufficient private incentives to introduce or to subscribe to this service. Market failures of this type are more likely to occur in network industries where consumption benefits depend on the number of other consumers and firms that provide the service.

Gowrisankaran and Stavins (2004) have investigated empirically the degree to which the adoption of $\mathrm{ACH}$ by banks exhibits network effects and have found evidence that network externalities exist and are moderately large. Clearly, this is only one side of the story, because transactions among consumers and small businesses may exhibit even stronger network effects. Once 
a consumer receives some money from a friend via $\mathrm{ACH}$, the consumer is likely to investigate whether she can also use this system to transfer money herself. If this consumer happens to run a small business, she may wonder why her business is not using the same means of payment to collect fees from her clients and she may decide to accept the system. Replicated over many individuals, this kind of experience could lead to the emergence of a new market for direct accountto-account online transfers that could change the way small businesses pay and receive payments. As more and more merchants and buyers become more comfortable with B2P and P2B online and mobile transfers, positive momentum of network externalities could create a snowball effect.

\subsection{Direct A2A money transfers}

Several authors of earlier papers have identified the missing market associated with the nonavailability of online A2A transfer services to most U.S. bank account holders. This potential market failure has been associated with different types of electronic money transfer services: ${ }^{3}$

1. Biehl, McAndrews, and Stefanadis (2002) examined the causes of the low use of FedWire funds transfers and found the primary cause to be commercial banks' significant price markups over marginal cost.

2. Shy (2010) noted to the lack of online use of A2A electronic funds transfer via automated clearing houses $(\mathrm{ACH})$.

3. With the successful and rapid adoption of the immediate funds transfer network (IFT) in England, Summers and Wells (2011) investigated whether a similar payment network should be developed in the United States.

4. Windh (2011) pointed out a lack of standardization in the emerging P2P money transfer platforms in the United States, and the resulting confusion among individuals and small businesses.

\footnotetext{
${ }^{3}$ FedWire Funds Service is provided by the Federal Reserve Bank to commercial banks to send or receive timecritical payments for their own account or on behalf of corporate or individual clients; see http: //www.frbservices . org/fedwire/index.html. An ACH network is a low-cost, batch processing, store-and-forward system that provides for the interbank clearing of electronic payments for participating depository financial institutions; see http://www . nacha.org.
} 
Although the lines of research mentioned above focused on somewhat different electronic payment networks, all raise a common question: why for so many years did commercial banks in the United States fail to provide account holders with a uniform-standard, low-cost interface that would allow them to make electronic funds transfers from their own bank account to a different person with a different bank account in any bank in the United States? Low-cost here should be interpreted as a fee sufficiently low to lure households away from using paper checks and third party services for A2A money transfers. Although most commercial banks do offer FedWire services, as mentioned above, they tend to charge prices that are prohibitively costly for regular use. As for ACH transfers, most banks do not even offer their customers the interface for making A2A transfers, despite the fact that $\mathrm{ACH}$ transfers are the least costly transfer method for commercial banks. In fact, frustration with the inefficient payment systems in general and with the nonavailablity of A2A electronic transfer services in the United States in particular, goes back almost 40 years. Quoting from (Hester, 1972, p. 286):

In this system every commercial establishment would have a small teletype device hooked into a large data processing facility, regional or national, where both the payer and the recipient had an account. After agreeing on some transaction both individuals would approach a terminal and cause an instantaneous transfer from the payer to the recipient, if the payer's balance is sufficient. The major advantage of such a system is that clearing would become a real-time phenomenon; float would vanish and no one could overdraw his account. Further...no paper would be generated through clearing.

Furthermore, Hester (1972, p.286) was also able to visualize the network economies associated with electronic funds transfers:

Since the processor always simultaneously debits and credits accounts,...there is no reason why the data processor need belong to the banking industry or the Federal Reserve; it could just as easily be operated by the Post Office as happens in the GIRO system.

A referee of this paper raised the possibility that the (missing) market is beginning to "correct itself" as we now witness more and more financial institutions offering A2A money transfer services to their online customers. I discuss these services in Section 4, as they tend to differ across different financial institutions. More precisely, the relatively small number of commercial banks that do offer A2A transfer services tend to use different technologies, which require transfer 
recipients to register with different payment services.

\subsection{Indirect A2A money transfers}

Although direct A2A transfers were either not offered by commercial banks, or were prohibitively costly, households in the United States were still able to perform some indirect money transfers. As mentioned above, Foster et al. (2011) report that P2P transfers constituted 5 percent of total payments and that 0.8 percent of the respondents reported using debit and credit cards for P2P money transfers. Because card networks rarely provide card-to-card transfer services, a possible explanation for this finding is that households use debit and credit cards to fund accounts held with nonbank money transmitters, which are then used for person-to-person money transfers and for person-to-small-business payments.

One possible conclusion from this discussion could be that commercial banks did not rush to introduce low-fee direct A2A money transfer services via online banking because they did not view A2A transfers as an essential service. This was the case with earlier introductions of online banking, in which several banks chose not to adopt at the beginning. Another possible explanation is that banks may have concluded that indirect transfers funded by cards are more profitable to them than direct transfers because card-issuing banks collect interchange fees that are proportional to the dollar value of the transfers. Note that this explanation is incomplete, because money transmitters recover the interchange fees they pay card issuers from households. This leaves the question: why did commercial banks not offer direct transfers at slightly lower fees than the interchange fees?

Over the years some households in the United States have figured out how to use online bill payment for P2P transfers. Under this type of indirect transfer, consumers enter information online but banks send paper checks to payees. This type of transfer can be classified as "digital-topaper" and is indirect because the transfer recipients have to travel or mail the paper check to the bank in order to complete the transfer. 


\section{International Comparisons}

Section 2 discussed the possible missing market associated with the lack of use of electronic A2A funds transfers. A natural question that follows from this discussion is: to what degree does the use of payment instruments in the United States differ from the experience of other countries? As already noted and as explained in Humphrey, Pulley, and Vesala (2000), Litan and Baily (2009), and others, payments in the United States used to be dominated by paper checks, in contrast with the situation in many European countries, which make extensive use of electronic funds transfers. Schuh and Stavins (2010) document recent reductions in the use of checks in the United States.

Figure 1 compares the percentage of A2A transactions out of the total number of transactions among 20 countries. Note that because the focus of this paper is A2A credit transfers, the figures

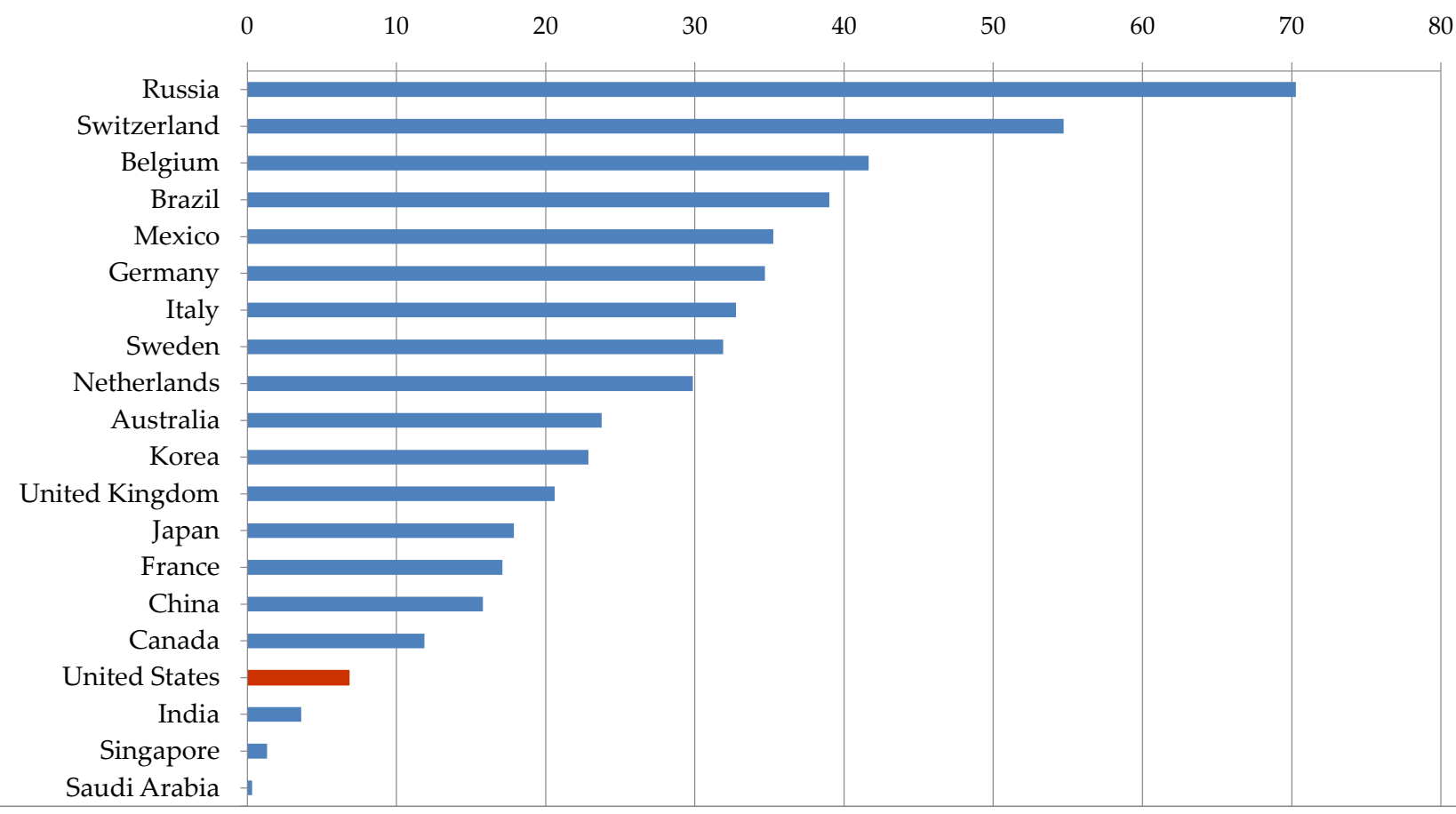

Figure 1: Credit transfers in 20 countries (percentage of number of transactions). Source: Bank of International Settlements.

may overstate the number of A2A transactions, because some direct debit transactions may be associated with online bill payments. However, as pointed out by a referee, assuming that direct debit transactions are proportional to credit transactions would leave the relative position of each 
country unchanged. ${ }^{4}$ Figures 2 modifies the ranking of the 20 countries in Figure 1 to percentages of dollar values (rather than the number of A2A transactions. The United States has the fourth-

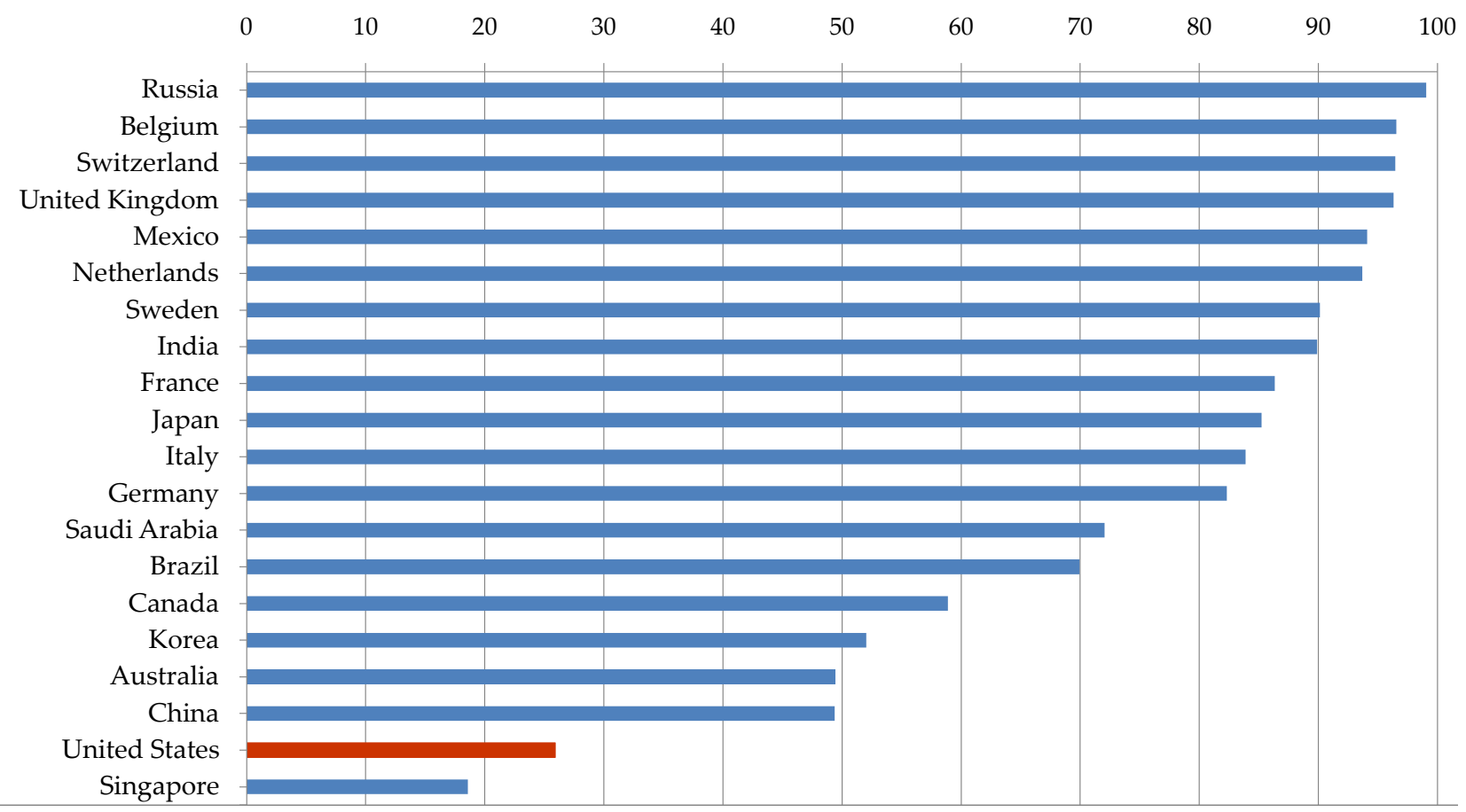

Figure 2: Credit transfers in 20 countries (percentage of value of transactions). Source: Bank of International Settlements.

lowest percentage of A2A transactions (less than 6.8 percent, see Figure 1); and with the exception of Singapore, the United States has the lowest percentage of A2A funds transfers in terms of dollar value (around 25.9 percent; see Figure 2).

Finally, Shy (2010) presents more detailed data, such as a comparison of the per-inhabitant yearly number of transactions associated with three noncash payment instruments: checks, credit transfers and direct debit (classified as $\mathrm{ACH}$ operations in this paper), and plastic cards, for a sample of 12 developed countries. The differences in the number of transactions among countries

\footnotetext{
${ }^{4}$ The Bank of International Settlements glossary (www.bis.org/publ/cpss95.htm) defines credit transfer as a payment order made for the purpose of placing funds at the disposal of the beneficiary. Both the payment instructions and the funds described therein move from the bank of the payer/originator to the bank of the beneficiary, possibly via several other banks, as intermediaries and/or via more than one credit transfer system. Direct debit is a preauthorized debit on the payer's bank account initiated by the payee; examples include online bill payment and preauthorized transfers from individuals to financial institutions. I interpret credit transfers as all other electronic transfers similar to $\mathrm{ACH}, \mathrm{EPN}$, and Fedwire in the United States.
} 
may reflect differences in the use of cash as a means of payment. ${ }^{5}$

\section{Recent Developments in the United States}

Commercial banks in the United States were very late to begin introducing A2A money transfer services relative to other countries. Section 3 provided some international comparisons that support this observation. For some reason, commercial banks in the United States did not view A2A money transfers as a revenue generating or essential service that could be integrated with online banking. Commercial banks started introducing A2A transfer services only in the past two years, after they realized that they face competition on these services from nonbank money transmitters, such as PayPal, and potential competition stemming from recent developments in mobile banking in the direction of electronic money transfer and payment services.

Possible reasons for this late involvement of U.S. banks are analyzed extensively in Shy (2010), which attributes it to: (a) banks' failure to observe the potential revenue that can be generated from A2A transfers by implementing proper differential pricing strategies, (b) the transition from paper check clearing to the use of image check clearing (commonly referred to as check truncation, or substitute checks), which expedited check clearing (following the Check 21 Act of 2003), ${ }^{6}$ (c) lack of intervention by the Fed to encourage banks to use the inexpensively provided ACH by integrating A2A money transfers via the $\mathrm{ACH}$ with their online banking services, and (d) households' perception that the exchange of bank account numbers is dangerous (despite the fact that paper checks also provide the same information). The last barrier is now somewhat mitigated because households that were initially unwilling to disclose their bank account information in order to receive money are willing to join networks that substitute email or mobile phone number for account information disclosed to senders. In these networks, receivers can input their bank account details without having to disclose them to senders.

\footnotetext{
${ }^{5}$ It would be interesting to compare the dollar value per electronic credit transaction among these countries. However, because we do not have the distributions of the billions of individual transaction values, we are unable to compute the median transaction value in each country (and other percentiles). Computations of average transaction values yield high numbers (in the thousands of dollars) and therefore do not reveal very much about how electronic credit transactions are actually used in each country.

${ }^{6}$ Although Schuh and Stavins (2010) show that check use is declining, Table 25 in Foster et al. (2011) shows that in $2009,0.8 / 5=16$ percent of P2P transfers were made via paper checks.
} 
During the past two years, a few commercial banks in the United States began introducing new interfaces that enable account holders who use online banking to electronically transfer money from their own bank account to other bank accounts. In fact, Bank of America (the largest in terms of total U.S. deposits) already announced this service in August 2009. ${ }^{7}$ ING Direct followed. ${ }^{8}$ Bank of America, JPMorgan Chase, and Wells Fargo have announced that they have formed a new P2P payments joint venture called clearXchange. ${ }^{9}$ About 200 banks, including Bank of the West, Citibank, and PNC, use Popmoney technology for transfers among accounts within this group of banks. ${ }^{10}$ Thus, some banks allow their customers to transfer to any account in any bank within the United States, whereas others form joint ventures in which transfers are restricted to accounts held within the contracting banks. Windh (2011) provides a more detailed description of these emerging A2A money transfer networks.

While it may be too early to tell whether these innovations signal a major change in attitude of commercial banks and the American consumer toward the way that money moves between accounts, these changes open up opportunities for individuals, consumers, and small businesses to substitute cash, checks, and payment cards (outside the point of sale) with electronic funds transfers. In fact, several papers, such as D'Silva (2009), predict that the availability of low-cost online P2P transfers is where the industry is heading, especially because domestic payments between individuals in the United States are currently estimated to be around $\$ 2.9$ trillion annually.

Why did commercial banks in the United States wait so long to start integrating A2A money transfers into online banking? One explanation could be that banks finally realized that gaining a share in the A2A transfer market may be profitable. Another explanation could be that banks began internalizing a prediction that revenue from debit and credit cards will decline, following recent legislation and settlements with card companies. ${ }^{11}$ This explanation is rather incomplete

\footnotetext{
${ }^{7}$ See infocenter. bankofamerica.com/ic2/online-banking/transfer-funds-outside-bank.

${ }^{8}$ For a demo of P2P transfer see home.ingdirect.com/products/htmls_content/demo_p2p.html.

${ }^{9}$ Customers of the three banks will be able to move funds directly from their existing checking accounts using an email address or mobile number instead of providing checking account and routing numbers; see clearxchange.com. Chase has also introduced its own interface called QuickPay; see chase.com/online/services/quickpay.htm.

${ }^{10}$ Account holders of banks that offer Popmoney can send and receive money directly through their banks' online and mobile banking site. See popmoney. com.

${ }^{11}$ For debit cards, the Durbin Amendment to the 2010 Dodd-Frank Wall Street Reform and Consumer Protection Act (H.R. 4173, Sec. 1075) authorizes the Federal Reserve Board to limit the amount of interchange fees charged by card issuing banks. For credit cards, a 2011 settlement between the U.S. Department of Justice and Visa and MasterCard
} 
because the substitution between online A2A money transfers and payments made by debit and credit cards could be low; if this is the case, then online A2A transfer opens a new market rather than taking business away from debit and credit cards, which are used mostly at points of sale and less frequently via the Internet. The substitution between payment cards and online A2A transfers may occur when consumers prefund an account with a money transmitter for the purpose of sending money to another person or a small business, as described in the paragraph below.

A significant share of money transfers in the United States is initiated outside the banking industry. Money transmitters, such as PayPal, provide their registered users with an online interface to transfer money among registered users. Senders can fund their transfer from their bank accounts without paying a fee, or by a credit card (for a fee). Receivers can then transfer their balance to their bank account or spend it using a debit card. A similar service is now offered by the online retailer Amazon and by OboPay whereby registered buyers can send and receive money and fund it from their bank accounts. ${ }^{12}$

To summarize, at present, the few commercial banks offering online A2A money transfers use different networks. These newly formed networks are either "send-open," in the sense that senders can transfer money to any other bank in the United States, or limited to banks participating in the specific network. ${ }^{13}$ Parallel to commercial banks, established and newly entering money transmitters continue to provide a large fraction of online money transfers.

\section{Analytical Examples of A2A Payment Networks}

A2A money transfers can be viewed as a "network good (service)," in which the utility of each payer (and payee) increases with the number of other payers and payees who subscribe to the

allows merchants to steer buyers away from costly credit cards; see Schuh et al. (2011).

${ }^{12}$ See paypal.com, payments . amazon.com/sdui/sdui/personal/money, and obopay.com.

${ }^{13}$ Diverse standards are also observed in the emerging market for point-of-sale mobile payments. The September 2011 issue of Consumer Reports mentions that Google plans to launch its version in which a Nexus S 4G phone from Sprint with a downloadable Google Wallet application will let users pay for purchases with Citi PayPass-eligible MasterCards or with a Google Prepaid Card by tapping the phone on a PayPass terminal. At least three competing digital wallets are planned for launch later this year and in 2012: from Visa in partnership with more than a dozen banks; Isis, a joint venture of AT\&T Mobility, T-Mobile, and Verizon Wireless; and PayPal Mobile's point-of-sale technology. However, retailers are not rushing to buy the equipment necessary to link a customer's cell phone to their cash registers, because they need to see a dollars-and-cents advantage. 
same or a compatible payment network. ${ }^{14}$ Under network externalities, various market failures can emerge. The first is a supply side failure in which commercial banks do not introduce A2A transfer services although these services could become profitable if all banks jointly introduced them. The second possible failure involves substitution between payment instruments, where switching from cash and checks to online A2A transfers could enhance user welfare, but individuals choose not to switch.

The analytical examples developed below abstract from the above potential failures, and instead focus on a third possible failure that arises from the coexistence of multiple incompatible payment networks. This section constructs simple analytical examples with the following goals:

(a) To demonstrate equilibria in which multiple incompatible payment networks can coexist.

(b) To derive the conditions on network connection costs and payers' preferences for payment network size under which aggregate user surplus is enhanced when users register with multiple incompatible payment networks.

This demonstration is important because it identifies the conditions under which individual payers do not find it beneficial to register with multiple payment networks, although, due to the prevailing network externality, aggregate user surplus would be enhanced if some payers registered with multiple networks.

\subsection{Payment networks promoted by commercial banks}

Consider $4 N$ payers who are equally distributed among four financial institutions. More precisely, $n_{A}=N$ payers have accounts with bank $A, n_{B}=N$ with bank $B, n_{C}=N$ with bank $C$, and $n_{D}=N$ with bank $D$. There is a probability, $p(0<p<1)$, that each payer will want to make a payment to each individual in this economy. Figure 3 displays a scenario where banks $A$ and $B$ and banks $C$ and $D$ form two separate incompatible payment networks. ${ }^{15}$ Each payer's utility is assumed to be increasing with the expected number of payments that can be made on the payer's

\footnotetext{
${ }^{14}$ See Shy $(2001,2011)$ and their references for definitions and classifications of network externalities. The demand for network goods and services was first analyzed in Rohlfs (1974) in the context of consumer demand for subscription telecommunication services.

${ }^{15}$ The reader may wonder why the example displayed in Figure 3 assumes that the money transmitter's platform is larger than the $\overline{A B}$ and $\overline{C D}$ platforms. The FDIC Call Report states that in June 2011 there were 598, 230, 155 deposit accounts in the United States, and that Bank of America (the largest bank in terms of assets and deposits) had 62, 630,658 accounts, a smaller number than PayPal's 100 million estimated number of accounts.
} 

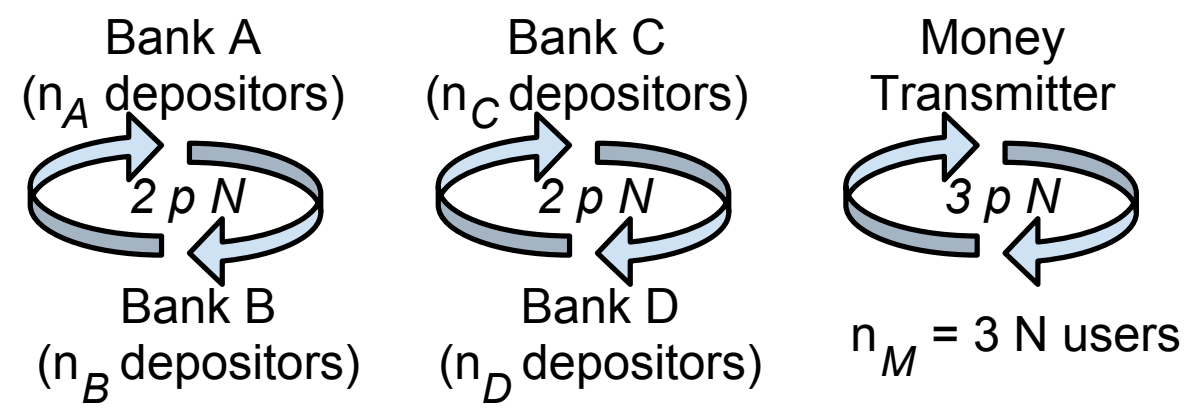

Figure 3: Independent payment networks. Note: The money transmitter should be disregarded for the first example.

payment network. Formally, if the total number of payees connected to the payer's networks is $n$, then the payer's utility can be defined by

$$
U(n) \stackrel{\text { def }}{=} \sqrt{p n}
$$

where $p n$ is the number of A2A money transfers that the payer is expecting to make.

Bank customers fund their transfers directly through their bank accounts. All banks can connect to a nationwide $\mathrm{ACH}$ network; therefore, banks are able to provide A2A money transfer service to any other bank account, if they wish to do so. In contrast, sending money via money transmitters (analyzed in Section 5.2) must be funded from external sources, such as bank accounts (via $\mathrm{ACH}$ ), credit cards, or debit cards.

Figure 3 shows that each payer is connected to $2 N$ potential payees. This connection is assumed to be integrated with account holders' online banking and thus provided at no additional cost. Therefore, each payer expected to send money to $2 p N$ payees. Thus, each payer's initial utility is $U_{A}^{0}\left(n_{A}+n_{B}\right)=U_{B}^{0}\left(n_{A}+n_{B}\right)=U_{C}^{0}\left(n_{C}+n_{D}\right)=U_{D}^{0}\left(n_{C}+n_{D}\right)=\sqrt{2 p N}$. Let $c$ denote the cost incurred by a payer when connecting to a second incompatible payment network. This cost could be generated by the effort and time needed to register with a second network. Therefore, if a payer belonging to the $\overline{A B}$ payment network also registers with the $\overline{C D}$ network, the payer is connected to $4 N$ potential payees and gains a utility level

$$
U_{A}^{1}\left(n_{A}+n_{B}+n_{C}+n_{D}\right)=U_{B}^{1}\left(n_{A}+n_{B}+n_{C}+n_{D}\right)=\sqrt{4 p N}-c .
$$


Hence, this payer will choose to connect to a second payment network if

$$
\begin{aligned}
& U_{A}^{1}=U_{B}^{1}=\sqrt{4 p N}-c>\sqrt{2 p N}=U_{A}^{0}=U_{B}^{0}, \quad \text { or, } \\
& \quad c<\bar{c} \stackrel{\text { def }}{=}(2-\sqrt{2}) \sqrt{p N} \approx 0.58 \sqrt{p N} .
\end{aligned}
$$

Reversing the inequality in (2) yields the following result.

Result 1. An equilibrium with multiple incompatible payment networks exists if $c \geq \bar{c}$.

Thus, unless the cost of signing up for an additional payment network is sufficiently low, the payers illustrated in Figure 3 will be split between two incompatible payment networks, each capable of serving only half of the population.

Turning to the discussion of efficiency, I now investigate whether and under what conditions adding a second network for half the payers (so that all payers will be on the same network) increases aggregate user surplus. To get all payers on a single network it is sufficient to have all payers belonging to the $\overline{A B}$ payment network also register for the $\overline{C D}$ network (or the other way around). These additional registrations enhance aggregate user surplus if

$$
4 N \sqrt{4 p N}-2 N c>2 N \sqrt{2 p N}+2 N \sqrt{2 p N}, \quad \text { or, } \quad c<\hat{c} \stackrel{\text { def }}{=}(4-2 \sqrt{2}) \sqrt{p N} \approx 1.17 \sqrt{p N} .
$$

The left-hand term in (3) measures the sum of utilities of $4 N$ payers when they are all connected to the same network, net of the cost of $2 N$ payers registering with a second payment network. The term to the right is the aggregate utility of $2 N+2 N$ payers, where each payer can transfer money to only half the payee population.

The following result is obtained directly from the conditions set forth in (2) and (3).

Result 2. An adoption failure occurs at intermediate values of a payer's cost of registering with a second payment network $(\bar{c}<c<\hat{c})$. In this case, the market outcome is such that each payer is registered with only one payment network whereas registering half of the payers with a second network (100 percent connectivity) enhances user surplus.

Figure 4 displays the region of the cost parameter under which this adoption failure occurs. Figure 4 shows that there is no adoption failure at low and and high cost levels. For $c<\bar{c}$ half 


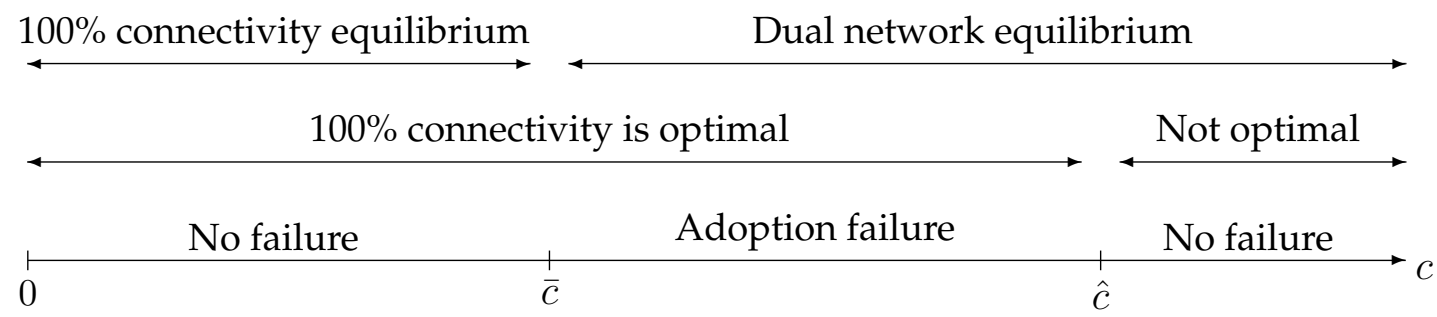

Figure 4: Equilibrium versus optimum as a function of second network registration cost, $c$.

of the payer population will register with a second network thereby achieving 100-percent connectivity among all payers in the economy, which is optimal. For $c>\hat{c}$, registering half of the population with a second network is neither optimal nor an equilibrium, because of the high cost level. An adoption failure occurs at intermediate values of the cost parameter, where registering half the payers with a second network enhances aggregate payer surplus due to the prevailing network (adoption) externality; however, in equilibrium no payer has an incentive to incur this cost.

\subsection{Networks offered by banks and money transmitters}

The above example is fairly general in the sense that it can analyze more complex hybrids of payment networks, such as those emerging in the United States. Payment networks such as PayPal and Amazon Payments, are not banks and are licensed as money transmitters in each state. To send or receive money, both the payer and the payee must be registered with the same network. Figure 3 adds a third independent payment platform, which is provided by a money transmitter, to the previous analysis.

In view of Figure 3, a payer who is registered with network $\overline{A B}$ (similarly, $\overline{C D}$ ) will also register with the money transmitter's network if

$$
\sqrt{5 p N}-c \geq \sqrt{2 p N}, \quad \text { hence if } c \leq c^{L} \stackrel{\text { def }}{=}(\sqrt{5}-\sqrt{2}) \sqrt{p N} \approx 0.82 \sqrt{p N}
$$

However, if all $\overline{C D}$ network users also register with the money transmitter, then (4) becomes

$$
\sqrt{7 p N}-c \geq \sqrt{2 p N}, \quad \text { hence if } c \leq c^{M} \stackrel{\text { def }}{=}(\sqrt{7}-\sqrt{2}) \sqrt{p N} \approx 1.23 \sqrt{p N} \text {. }
$$


Finally, payer surplus is enhanced when all bank account holders (platforms $\overline{A B}$ and $\overline{C D}$ ) also register with the money transmitter if

$$
\begin{aligned}
& 7 N \sqrt{7 p N}-4 N c \geq 2 N \sqrt{2 p N}+2 N \sqrt{2 p N}+3 N \sqrt{3 p N}, \text { hence if } \\
& c \leq c^{H} \stackrel{\text { def }}{=}\left(\frac{7 \sqrt{7}-3 \sqrt{3}}{4}-\sqrt{2}\right) \sqrt{p N} \approx 1.91 \sqrt{p N} .
\end{aligned}
$$

Figure 5 displays the region of the cost parameter under which this adoption failure occurs. The

$$
\begin{aligned}
& \text { 100\% connectivity } 2 \text { equilibria _ Dual network equilibrium }
\end{aligned}
$$

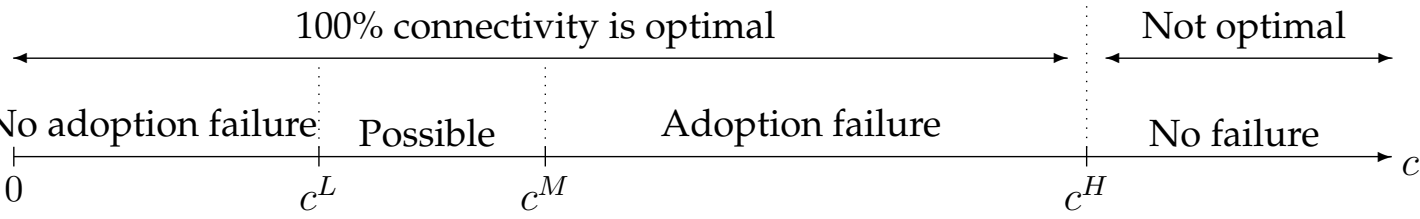

Figure 5: Equilibrium versus optimum with multiple payment networks.

costs of registering with an additional network defined in (4) and (5) determine a range in which there are two possible equilibria. One equilibrium reflects an adoption failure where all bank account holders (networks $\overline{A B}$ and $\overline{C D}$ users) would benefit if they all registered with the money transmitter, but they choose not to do so (because they expect no one else to do so). In the second equilibrium, all bank account holders do register with the money transmitter and this adoption failure is avoided. The remaining three regions can be interpreted in the same way as the simpler example displayed in Figure 4. That is, an adoption failure does not prevail for sufficiently low cost $\left(c<c^{L}\right)$, where all bank account holders will register with the money transmitter, or for sufficiently high $\operatorname{cost}\left(c>c^{H}\right)$, where registering with a single payment network is both the market outcome and optimal. Otherwise, for $c^{M}<c<c^{H}$, an adoption failure exists where each payer is registered with only one network, but this equilibrium is not optimal from the payers' point of view. 


\subsection{Payer versus payee utility: An extension of the model}

The previous analysis was simplified by ignoring the different benefits that payers and payees may derive from A2A money transfers. This section modifies the utility function so that it can measure separately the benefits from sending money and receiving money. Formally, the utility of an individual with network connections that provide access to $n^{S}$ individuals to whom she can send money, and to $n^{R}$ individuals from whom money can potentially be received, can be defined as

$$
U\left(n^{S}, n^{R}\right) \stackrel{\text { def }}{=} \sigma \sqrt{p n^{S}}+\rho \sqrt{p n^{R}},
$$

where $\sigma, \rho>0$ are the weights on the degree of importance individuals attach to the ability to send and receive money via $\mathrm{A} 2 \mathrm{~A}$ transfers.

To demonstrate the difference between the separable utility function (7) and utility function (1), let us concentrate only on the two A2A payment networks provided by commercial banks, illustrated on the left part of Figure 3. However, suppose now that: (i) payment network $\overline{A B}$ is "send open" in the sense that all bank $A$ and bank $B$ customers can use online banking to access the $\mathrm{ACH}$ in order to send money to any account holder nationwide (including sending money to customers of banks $C$ and $D$ ) and (ii) payment network $\overline{C D}$ is an "on-us" network meaning that transfers between customers of banks $C$ and $D$ are done directly on the two banks' mainframes without involving third parties, such as ACH networks.

To demonstrate an application of the utility function (7), observe that customers of banks $A$ and $B$ can send money to any bank account nationwide; formally, $n_{A}^{S}=n_{B}^{S}=n_{A}+n_{B}+n_{C}+n_{D}=$ $4 N$. However, bank $A$ and bank $B$ customers can receive money only from $A$ and $B$ customers; formally, $n_{A}^{R}=n_{B}^{R}=n_{A}+n_{B}=2 N$. The opposite holds for customers of bank $C$ and bank $D$. They can send only to customers of banks $C$ and $D$, so $n_{C}^{S}=n_{D}^{S}=n_{C}+n_{D}=2 N$, but they can receive money from any bank account nationwide, so $n_{C}^{R}=n_{D}^{R}=n_{A}+n_{B}+n_{C}+n_{D}=4 N$. Therefore, utility levels are given by

$$
\begin{aligned}
& U_{A}=U_{B}=\sigma \sqrt{p\left(n_{A}+n_{B}+n_{C}+n_{D}\right)}+\rho \sqrt{p\left(n_{A}+n_{B}\right)}=\sigma \sqrt{4 p N}+\rho \sqrt{2 p N} \\
& U_{C}=U_{D}=\sigma \sqrt{p\left(n_{C}+n_{D}\right)}+\rho \sqrt{p\left(n_{A}+n_{B}+n_{C}+n_{D}\right)}=\sigma \sqrt{2 p N}+\rho \sqrt{4 p N} .
\end{aligned}
$$


Notice that the degree of asymmetry with respect to the utility gain from sending money and receiving money, as captured by the parameters $\sigma$ and $\rho$, determines users' incentives to register with a second payment network. For example, if consumers place high utility on being able to receive money (compared with sending money), so that $\rho$ is significantly larger than $\sigma$, then customers of banks $A$ and $B$ will have a strong incentive to register with the $\overline{C D}$ network, whereas customers of banks $C$ and $D$ will have a weak incentive to register with the $\overline{A B}$ payment network. In contrast, customers of banks $C$ and $D$ will have a strong incentive to register with the $\overline{A B}$ payment network if $\sigma$ is significantly larger than $\rho$.

\section{Policy Options}

Section 2 has discussed previous literature suggesting the possibility of a missing market associated with the lack of use of A2A money transfers in the United States. To remedy this possible market failure, three policy options may be worth considering:

No intervention: Taking no action means leaving the market to continue to develop by itself with multiple platforms that sooner or later may (or may not) integrate into a national network.

Intervention: Allowing a third party, such as the Fed, to create incentives for commercial banks to provide their account holders with low-fee access to the ACH and FedWire. In fact, Biehl, McAndrews, and Stefanadis, 2002, p.3 (henceforth BMS) have already argued for this option: "We feel that understanding the end-user experience, and creating incentives for banks to provide innovative and more efficient end-user facilities should be a high priority for the Federal Reserve."

Creating a completely new network: Constructing a new nationwide payment network that connects to all bank accounts identified by ABA numbers.

Regarding the second policy option (intervention), BMS recommend that the Fed

Encourage innovations that increase accessibility and reduce the cost of a transfer for retail customers. This may involve actively assisting banks with ongoing improvements to their user interfaces, disseminating information, or even participating with bank and manufacturing consortia that wish to increase the efficiency 
of customer transfers by providing automated Fedwire entry machines. Pursue a more aggressive strategy of controlling the use of the Fedwire trademark. Evaluate coordinated bank marketing campaigns for the service. Actively explore the creation and publication of end-user directories, and work on better addressing systems for funds transfers.

As for the prohibitively costly prices commercial banks charge for FedWire services, BMS write the following:

One issue of great interest is the relatively high prices charged by commercial banks to their customers for completing a transfer. While the Federal Reserve charges banks less than $\$ 0.25$ per transfer, banks charge their customers prices that vary from a few dollars to as much as $\$ 50$.

Translating the above information to today's ACH prices, the Federal Reserve and the Electronic Payment Network (EPN) charge commercial banks around $\$ 0.003$ to receive or to send money via the ACH. FedWire charges $\$ 0.026$ to $\$ 0.52$ to send or receive money. ${ }^{16}$ Therefore, implementing differential pricing, such as fees that are proportional to the dollar value of the transactions could create a new market for A2A transfers. For the sake of illustration, banks could charge $10 \phi$ for transfers below $\$ 1000,20 \notin$ below $\$ 2000$, and so on. If, for example, banks kept households' A2A transfer fees below $44 \phi$, which is the current price of a postage stamp, some renters might switch to A2A for rental payments instead of mailing a paper check to their landlord with a $44 \phi$ stamp.

Note that the Monetary Control Act of 1980 does not allow the Fed to subsidize its ACH and FedWire services. Therefore, the Fed cannot merely reduce the fees charged to commercial banks for FedACH and FedWire transfers. ${ }^{17}$ However, within this constraint, over the years the Fed has been trying to induce commercial banks to reduce their fees on electronic transfers, by raising the fees on clearing checks. More recently, in 2011, FedWire began offering commercial banks significant fee discounts on FedWire transfers in the range of $\$ 0.026$ to $\$ 0.104$ (down from $\$ 0.13$ to $\$ 0.52$ ) if they increase their volume by 50 percent. ${ }^{18}$ At this point it is not clear whether commercial banks would use this type of incentive to discount low-value A2A transfers that households now make with checks and cash.

\footnotetext{
${ }^{16}$ See epaynetwork.com. FedACH and FedWire fees are listed on frbservices.org/servicefees/fedach services_2011.html and frbservices.org/servicefees/fedwire_funds_services_2011.html.

${ }^{17}$ See federalreserve.gov/paymentsystems/pfs_principles.htm.

${ }^{18}$ See, again, frbservices.org/servicefees/fedwire_funds_services_2011.html.
} 
Regarding the third policy option (creating a totally new payment network), Summers and Wells (2011) discuss a proposal that calls for the construction of a new immediate funds transfer (IFT) network in the United States. The proposed structure resembles the highly successful construction and adoption of the Faster Payments Service (FPS) in England. ${ }^{19}$ Work on the FPS started in 2005, and service began in 2008. This project was an outcome of a response by banks to a long-term complaint by the Office of Fair Trading about the cost and inefficiency (due to loss of float) associated with the previously used payment platforms in England.

The British FPS resembles FedWire in the United States in the sense that transfers are immediate and irrevocable. However, the fundamental differences are that the FPS concentrates on low-value transactions and commercial banks charge low fees, making this service affordable to households. In contrast, commercial banks in the United States charge relatively high fees to send and separately to a receive money transfer, making FedWire prohibitively costly for daily household use.

Constructing a completely new payment network in the United States has its pros and cons. If most major commercial banks would provide their customers with low (or no) fee access to a new payment network, as happened in the British case, such a network might be a significant improvement over the use of checks and cash and over the uncoordinated A2A money transfer services currently provided by commercial banks in the United States. However, if commercial banks will not provide their online customers with low-fee access to this network, such a network could function almost identically to the networks that are already provided by money transmitters because every transaction would have to be prefunded from households' external bank accounts.

More generally, is not clear why a newly constructed payment network would be superior to the existing and already highly efficient automated clearing house networks that most banks are already connected to. ${ }^{20}$ The main potential difference between a newly constructed IFT and online use of the ACH is the speed of settlement, although the Fed has already introduced a new service called Same-Day ACH. So the remaining question associated with the proposal to construct an IFT is: To what degree do account holders value the speed of funds transfers? In other words, does

\footnotetext{
${ }^{19}$ See ukpayments.org.uk/faster_payments_service and VocaLink and PriceWaterhouseCoopers (2009).

${ }^{20}$ See the Electronic Payments Association, nacha. org for more details.
} 
it matter to consumers if paying rent, a dentist's bill, or family transfers clear immediately or just overnight? Except for real estate transactions, it is possible that speed matters less to consumers than accessibility and low fees.

\section{Concluding Remark}

The market structure of A2A money transfers in the United States has emerged differently from the money transfer market in Europe and has taken a different, decentralized form. This decentralized market now consists of various groups of banks and isolated money transmitters, each operating a different network. Time will tell whether this decentralized market structure will lead to very slow adoption of A2A transfers by households and further slow the transition from cash and checks to electronic payments.

\section{References}

Biehl, A., J. McAndrews, and C. Stefanadis. 2002. "A review of the retail and wholesale markets for funds transfers." Working paper, Payments Studies Function, Federal Reserve Bank of New York.

D'Silva, V. 2009. "Payments in Flux: Megatrends reshape the industry." In Moving money: The future of consumer payments, eds. R. Litan and M. Baily. Washington D.C.: Brooking Institution Press.

Foster, K., E. Meijer, S. Schuh, and M. Zabek. 2011. “The 2009 Survey of Consumer Payment Choice." Federal Reserve Bank of Boston, Public Policy Discussion Paper No. 11-1.

Gowrisankaran, G., and J. Stavins. 2004. “Network externalities and technology adoption: lessons from electronic payments." RAND Journal of Economics 35(2): 260-276.

Hester, D. 1972. "Monetary policy in the "checkless" economy." The Journal of Finance 27(2): 279293. 
Humphrey, D., L. Pulley, and J. Vesala. 2000. “The check's in the mail: Why the United States lags in the adoption of cost-saving electronic payments." Journal of Financial Services Research 17(1): 17-39.

Litan, R., and M. Baily. 2009. "Introduction." In Moving money: The future of consumer payments, eds. R. Litan and M. Baily. Washington D.C.: Brooking Institution Press.

Rohlfs, J. 1974. "A theory of interdependent demand for a communications service." The Bell Journal of Economics and Management Science 16-37.

Schuh, S., O. Shy, J. Stavins, and R. Triest. 2011. "An Economic Analysis of the 2010 Proposed Settlement between the Department of Justice and Credit Card Networks." Federal Reserve Bank of Boston, Public Policy Discussion Paper No. 11-4.

Schuh, S., and J. Stavins. 2010. "Why are (some) consumers (finally) writing fewer checks? The role of payment characteristics." Journal of Banking and Finance 34(8): 1745-1758.

Shy, O. 2001. The economics of network industries. Cambridge University Press.

Shy, O. 2010. "Person-to-person electronic funds transfers: recent developments and policy issues." Federal Reserve Bank of Boston, Public Policy Discussion Paper No. 10-1.

Shy, O. 2011. "A short survey of network economics." Review of Industrial Organization 38(2): 1-31.

Summers, B., and K. Wells. 2011. "Emergence of immediate funds transfer as a general-purpose means of payment." Federal Reserve Bank of Chicago, Economic Perspectives 35: 97-112.

VocaLink, and PriceWaterhouseCoopers. 2009. "Tomorrow happened yesterday How banks are building a business case for Faster Payments." Report, available at http: //www.pwc.com/en_GX/gx/banking-capital-markets/transaction-banking-compass/ pdf/tomorrow-happened-yesterday.pdf.

Windh, J. 2011. "Peer-to-peer payments: Surveying a rapidly changing landscape." Federal Reserve Bank of Atlanta Discussion Paper. 